\title{
Characterization of the Protective Layer Formed on Zinc in Whole Blood
}

Karin Beaussant Törne ${ }^{1,2}$, Andreas Örnberg ${ }^{2}$, Jonas Weissenrieder ${ }^{1, *}$

1. Material Physics, Department of Applied Physics, KTH Royal Institute of Technology, Electrum 229, 16440 Kista, Sweden

2. Abbott, 177 E County Rd B, St. Paul, MN 55117, USA

*Corresponding author: jonas@kth.se

Keywords: zinc; electrochemical impedance spectroscopy (EIS); biodegradable metal; protein adsorption; protective layer formation; phosphate

\section{Abstract}

The advantageous degradation properties of zinc in a biological environment are related to the presence of a protective corrosion layer composed of both organic and inorganic components. However, the mechanisms governing its formation and how the organic species influence its properties have not been established. Here we study the protective layer formation during anodic polarization in whole blood by in situ electrochemical impedance spectroscopy (EIS) as well as infrared spectroscopy and scanning electron microscopy. Simulated body fluid (m-SBF) was used as a reference media to discern the influence of the organic species present in whole blood. Protective zinc phosphate layers form on the Zn surface in both solutions, but of different nature and through diverse mechanisms. In $\mathrm{m}$-SBF the passivating thin film formation occur already at open circuit potential, reducing the corrosion current compared to exposure in whole blood by a factor of $10^{3}$. The high corrosion current in whole blood can be explained by a process including rapid protein adsorption preventing the initial formation of a protective phosphate layer. EIS analysis detected an inductive arc in whole blood at low overpotentials, before the onset of protective film formation, indicating the presence of adsorbed $\mathrm{Zn}$ 
ions. The coverage of $\mathrm{Zn}$ ions approach $100 \%$ of the active surface at $110 \mathrm{mV}$. At this critical surface coverage a reaction between the adsorbed $\mathrm{Zn}$ ions and $\mathrm{PO}_{4}{ }^{2-}$ takes place which results in formation of a protective, porous, film of $\sim 1 \mu \mathrm{m}$ thickness. The inorganic component of the protective film formed in whole blood was characterized as $\mathrm{Zn}\left(\mathrm{PO}_{4}\right)_{2}(\mathrm{OH})_{2} \cdot 3 \mathrm{H}_{2} \mathrm{O}$.

\section{Introduction}

In recent years zinc has received growing interest as a potential material in biodegradable applications.[1] Metals generally possess higher tensile strength compared to degradable polymers and are therefore attractive for cardiovascular, orthopedic and pediatric applications.[2-4] The majority of research on biodegradable metals have focused on magnesium and iron.[5] However in vivo studies of iron show formation of voluminous corrosion products which do not appear to be effectively degraded or in any other way removed by the biological environment.[4, 6] In addition, the degradation rate of iron was shown to be too slow for several applications. Magnesium on the other hand degrades quickly and is associated with rapid loss of mechanical stability. The rapid corrosion of magnesium is also associated with release of hydrogen gas which raises concerns for biocompatibility.[7] Magnesium alloys are further sensitive to stress corrosion cracking which may cause unpredictable failures of implants subjected to loads.[8, 9] In 2011 Vojtech et al. suggested zinc as an alternative metal to magnesium and iron.[10] Both in vivo and in vitro studies show zinc to possess a corrosion rate in the order of tens of microns per year, suitable for stent and bone applications.[10-12] Several in vivo studies also demonstrate favorable biocompatibility of zinc and zinc alloys.[10, 12-14] Li et al found no inflammatory response around zinc alloy implants in rat femur and new bone formation after one week.[13] Zinc wires implanted in rat aorta were found to not induce any contributors to restenosis such as necrosis or aggressive intimal hyperplasia.[15] Potential concerns have been raised regarding the toxicity of zinc. Although the tolerance limit for zinc is lower than the comparable levels for magnesium and iron the amount of zinc released from an implant of the size of a bone screw would be well below the recommended daily intake.[10]

Both in vivo and in vitro models have shown formation of a protective layer of corrosion products on zinc.[11, 14] This layer appears to incorporate organic, e.g. proteins and cells, as well as inorganic 
components formed by the reaction of $\mathrm{Zn}^{2+}$ with ions present in the surrounding environment.[11] A detailed understanding of the formation and nature of this protective layer is of vital importance to prediction of the corrosion mechanism of zinc implants in a clinical situation. In our previous paper zinc was observed to form a passive layer during potentiodynamic polarization (PDP) in human whole blood.[11] The passivation is manifested as a decrease in anodic current with increasing anodic potential and suggests the formation of a protective layer due to the anodic reaction. Samples polarized in inorganic buffer solutions (Ringer's solution and phosphate buffer saline) did not show similar passivation behavior, indicating the importance of the organic components in whole blood in the formation of the passive film. Here we study the mechanism determining the formation of the protective layer formation during anodic polarization by in situ impedance spectroscopy (EIS) and ex situ surface characterization by scanning electron microscopy (SEM) and Fourier transform infrared spectroscopy (FTIR). Analyzing the impedance response of the system at anodic polarization facilitates direct observation of the electrochemical processes involved in the protective layer formation. To support the impedance analysis ex situ investigation of surfaces obtained after application of different potentials was performed. The chemical composition of the surface layer was characterized by FTIR and the surface structure and cross sections were characterized by SEM. The protective layer formed during polarization is not directly correlated to the layer formed in a clinical situation. However, determining why this layer forms in whole blood and not in buffer solutions provide useful insights regarding the importance of organic components in the corrosion of zinc.

\section{Materials and methods}

Pure zinc samples (Goodfellow Inc) 99,9\% purity, were cut from zinc rods into discs of approximately $5 \mathrm{~mm}$ thickness and $12 \mathrm{~mm}$ in diameter. The samples were polished with $\mathrm{SiC}$ paper down to $4000 \mathrm{grit}$ prior to the electrochemical measurements. Citrated human whole blood was obtained from the Karolinska University hospital (Stockholm, Sweden). Modified simulated body fluid (m-SBF) was prepared according to the method described by Oyane et al. [16]

The electrochemical analysis was performed with a VMP2 potentiostat/galvanostat/ frequency response analyzer (BioLogic Science Instruments). All analysis was performed at room temperature and under ambient conditions. Every analysis was replicated at least three times. A three electrode flat 
cell with an $\mathrm{Ag} / \mathrm{AgCl}$ saturated $\mathrm{KCl}$ reference electrode and a Pt mesh counter electrode was used. A Luggin capillary was placed close to the sample surface to minimize the IR drop.

Three sets of electrochemical measurements were performed. First, potentiodynamic polarization scans were collected after $30 \mathrm{~min}$ immersion in the electrolyte. The scan was conducted from the open circuit potential (OCP) to $+250 \mathrm{mV}$ vs $\mathrm{OCP}$ with a scan rate of $0.02 \mathrm{mVs}^{-1}$. This comparably slow scan rate was chosen to allow sufficient time for the sample to reach steady state at every potential. In preliminary PDP scans conducted at higher scan rates the decrease in current density due to the formation of a protective layer was shifted towards higher anodic potentials and was not found to be as reproducible. The PDP scans in $\mathrm{m}-\mathrm{SBF}$ were aborted at $+150 \mathrm{mV}$ vs OCP due to the large increase in current density at even higher potentials.

In a second experiment impedance spectra were collected from $100 \mathrm{kHz}$ to $0.1 \mathrm{~Hz}$ with $2 \mathrm{mV}$ perturbation amplitude. $2 \mathrm{mV}$ perturbations were chosen in order not to deviate from the demand for linearity or induce irreversible changes to the sample surface (as determined in preliminary studies). No data points were collected below $0.1 \mathrm{~Hz}$ as even low perturbations applied for extended time periods (several seconds) may induce irreversible faradic currents inflicting permanent changes to the interface. The potential was incrementally increased from OCP to $+250 \mathrm{mV}$ in steps of $10 \mathrm{mV}$. The sample was held for $18 \mathrm{~min}$ at each step prior to the EIS measurement in order to allow the interface to reach a steady state. During this time the current stabilized indicating stability of the system.

From the impedance and PDP data four potentials of particular interest were chosen for the third measurement and ex-situ SEM and FTIR characterization, $+90 \mathrm{mV},+130 \mathrm{mV},+180 \mathrm{mV}$, and $+230 \mathrm{mV}$ vs OCP. A minimum of two samples per potential were held at constant applied potential for six hours. EIS spectra were collected after six hours to confirm that the formed surface was equivalent to the one formed in the potential step impedance spectroscopy. This result also serves to validate the electrochemical stability of sample during the impedance measurements as the obtained spectra after $6 \mathrm{~h}$ polarization (one impedance measurement) were equivalent to the spectra obtained during the potential incremental increase (several sequential impedance measurements). After the applied potential was aborted the samples were quickly removed from the whole blood and gently rinsed with deionized water prior to ex situ analysis. 
FTIR analysis of corrosion products was performed using a Thermo Scientific Nicolet iS10 with a universal attenuated total reflectance (ATR) accessory. For SEM analysis Carl Zeiss AG Ultra 55 with an Oxford Instrument INCA PentaFET x3 energy-dispersive X-ray spectroscopy (EDX) analyzer was used. Cross section views were produced by etching 5 x 5 x $5 \mu \mathrm{m}$ cubic holes with a focused Ga ion beam using a Quanta 3D FEG SEM.

\section{Results}

\subsection{Potendiodynamic polarization}

A representative PDP scan of zinc immersed in whole blood is presented in Figure 1. The open circuit potential is approximately $-1130 \mathrm{mV}$ vs $\mathrm{Ag} / \mathrm{AgCl}$ sat. $\mathrm{KCl}$ after $30 \mathrm{~min}$ immersion (point 1 in figure 1). During the anodic scan from OCP to $+90 \mathrm{mV}$ vs OCP, (point 2) the current steadily increases with increasing potential, a typical behavior in the Tafel region. Above $+110 \mathrm{mV}$ the current decreases with increasing potential to reach a constant value (approximately $6 \times 10^{-5} \mathrm{Acm}^{-1}$ ) at potentials above $+130 \mathrm{mV}$ (point 3). This reduction in current indicates the formation of a protective layer as a result of the application of the anodic polarization. Compared to the anodic passivation of stainless steel where the current density may decrease several orders of magnitude the observed current decrease (from $1 \mathrm{x}$ $10^{-4}$ to $6 \times 10^{-5} \mathrm{Acm}^{-1}$ ) is rather limited. The corrosion layer formed during the anodic polarization is therefore referred to as protective rather than passivating. At potentials above around $+210 \mathrm{mV}$ (point 5) an increase in current is observed, suggesting a breakdown of the protective layer. As the potential is further increased in the anodic direction formation of a second protective layer is observed at around $+230 \mathrm{mV}$ (point 6).

Scans performed in m-SBF, dashed line in insert of Figure 1, exhibit lower current density as compared to whole blood during anodic polarization until around $+130 \mathrm{mV}$ vs OCP. The OCP of zinc in $\mathrm{m}-\mathrm{SBF}$ after $30 \mathrm{~min}$ immersion is $-950 \mathrm{mV}$ vs $\mathrm{Ag} / \mathrm{AgCl}$ sat. $\mathrm{KCl}$. The PDP results and OCP is consistent with the presence of a passivating layer. Unlike the protective layer in whole blood the layer in m-SBF forms already at the corrosion potential. Above $+120 \mathrm{mV}$ the current density increases rapidly indicating the breakdown of the passive layer and onset of pitting corrosion. At $150 \mathrm{mV}$ the current reaches levels 10 times than that of samples exposed in whole blood.

\subsection{Impedance}


EIS spectra obtained in whole blood at potentials from OCP to $+230 \mathrm{mV}$ vs OCP are presented in Figure 2. At OCP (point 1 in Figure 1) the Nyquist plot consists of two capacitive semi circles. In our previous study on zinc in whole blood the high frequency arc is assigned to the charge transfer process and the double layer capacitance, whereas the low frequency arc was assigned to the rapid formation of a layer of inorganic corrosion products and adsorbed organic species on the sample surface. [11] The equivalent circuit (EC) depicted in Figure 4a describing a bilayer surface is used to fit the EIS spectra at OCP. Constant phase elements (CPE) are used rather than capacitators to compensate for surface inhomogeneity.[17] The CPE is defined as:

$$
C P E=\frac{1}{Q(j \omega)^{n}}
$$

Where $\mathrm{j}$ is the imaginary number and $\omega$ is the frequency. $\mathrm{Q}$ and $\mathrm{n}$ describe the properties of the CPE. If $\mathrm{n}$ is one the CPE is an ideal capacitator and $\mathrm{Q}$ has unit of $\mathrm{F} \mathrm{cm}-1$. In other cases $\mathrm{Q}$ has unit of $\mathrm{s}^{n} \Omega^{-1} \mathrm{Cm}^{-2}$. If $n$ is 0.5 the CPE is a Warburg element which describes a diffusion process. If $n$ is - 1 the CPE is an inductor. The $\mathrm{R}_{\mathrm{s}}$ element (Figure $4 \mathrm{a}$ ) describes the resistance of the whole blood (the electrolyte). $\mathrm{CPE}_{\mathrm{pl}}$ and $\mathrm{R}_{\mathrm{pl}}$ correspond to the capacitance and resistance of the organic layer respectively. $\mathrm{CPE}_{\mathrm{dl}}$ and $\mathrm{R}_{\mathrm{ct}}$ relate to the double layer capacitance and charge transfer process respectively. The result of the data fitting at all overpotentials is presented in table 1 in the supplementary information.

As the potential is increased from OCP to $+90 \mathrm{mV}$ vs OCP (point 2 in Figure 1) the radius of the high frequency arc, corresponding to $R_{c t}$, decreases as a result of the increasing anodic current (Figure 2). The radius of the low frequency capacitive arc decreases and is replaced by an inductive arc, observed as a negative arc at low frequencies. The EC used to model the impedance spectra, Figure $4 \mathrm{~b}$, describes the double layer capacitance as $\mathrm{CPE}_{\mathrm{dl}}$ and charge transfer resistance $R_{c t}$. $L$ and $R_{\mathrm{i}}$ describe the inductive arc. The inductive element observed during anodic polarization of zinc is generally ascribed to the relaxation of surface areas covered by adsorbed intermediates in response to the applied perturbation.[18] A comprehensive description on the origin of the inductive arc is provided in the discussion section. As the potential is further increased, the radius of the high frequency arc and the inductive arc increases and decreases respectively. At $+130 \mathrm{mV}$ vs OCP (point 3 in Figure 1) two capacitive arcs are observed in the spectrum (Figure 2). The low frequency capacitive arc can be described as a protective corrosion layer caused by the reaction of the adsorbed ions from the anodic dissolution with species in the whole blood electrolyte. The bilayer equivalent circuit, figure 4a, is used 
to interpret the spectra. As the potential is increased further to $+180 \mathrm{mV}$ vs OCP (point 4 in Figure 1) both the high and low frequency arc increase which can be interpreted as growth of the corrosion layer. The exponential term $\eta_{\mathrm{pl}}$ of the protective layer at $+180 \mathrm{mV}$ is 0.5 (Warburg element) which suggests diffusion limited process.

At $+210 \mathrm{mV}$ vs OCP (point 5 in Figure 1) the spectrum is characterized by two capacitive arcs and one inductive arc. The equivalent circuit in figure 4c is used to simulate the spectra. The inductive arc is interpreted as contribution from a partly protected surface, where inductive element describes the response of the unprotected surface area to the applied perturbation.[19] The partly protected surface is consistent with the observed protective layer breakdown and current density increase observed in the PDP measurements (Figure 1).

At $+240 \mathrm{mV}$ vs OCP two capacitive arcs with large radius characterize the EIS spectra. The increase in radius is consistent with the decrease in current density. The bi-layer equivalent circuit, Figure 4a, provides the best fit to the data. Both $\mathrm{R}_{\mathrm{ct}}$ and $\mathrm{R}_{\mathrm{pl}}$ increase and $\mathrm{R}_{\mathrm{pl}}$ increases by a factor of 10 compared to $\mathrm{R}_{\mathrm{pl}}$ at $+180 \mathrm{mV}$.

The impedance spectra of samples in $\mathrm{m}-\mathrm{SBF}$ are presented in Figure 3. Spectra obtained at OCP,+50 and $+130 \mathrm{mV}$ vs OCP are displayed to provide information on the effect of increasing potential on the impedance spectra before and after passivity breakdown. The spectrum at OCP is characterized by two capacitive arcs and large absolute impedance at low frequencies consistent with a passivated surface. As the potential is increased in the anodic direction the impedance spectra is found to consist of only one capacitive arc and the absolute impedance rapidly decreases with potential. No inductive arc was observed at any applied potential.

\subsection{SEM}

Representative SEM images of the surface and cross sections are presented in Figures 5 and 6 . In general the surfaces were homogenous and showed little variation between the samples polarized at the same potential. SEM images of samples polarized in whole blood at $+90 \mathrm{mV}$ (point 2 in Figure 1) vs OCP for $6 \mathrm{~h}$ show a corroded metallic surface without any precipitated corrosion product, consistent with the active dissolution as inferred from the analysis of the impedance spectra (Figure 5a). Small areas with dark appearance in SEM are observed randomly scattered over the surface. EDS analysis showes $\mathrm{Zn}$ and $\mathrm{O}$ to be present over the entire surface, as well as $\mathrm{C}, \mathrm{P}$ and S exclusively in the small 
dark areas. The dark regions are interpreted as dried remnants of proteins that are adsorbed over the entire surface during the immersion. Samples polarized at $+130 \mathrm{mV}$ (position 3 in Figure 1) show a thin homogenous layer of corrosion product which consists of $\mathrm{Zn}, \mathrm{O}, \mathrm{C}, \mathrm{P}, \mathrm{S}$ (from EDS). This is interpreted as the corrosion layer consisting of both organic and inorganic materials (Figure 5b). The corresponding FIB cross sections (Figure 6a) show a dense, very thin $(<1 \mu \mathrm{m})$ layer. The lines in Figure 6 indicate the location of the corrosion layer. The corrosion layer formed by polarization at $+180 \mathrm{mV}$ (position 4 in Figure 1) appears porous and mainly inorganic, consisting of Zn, P, and O (Figure 5c). Dark areas interpreted as adsorbed organic material is observed similar to the surface at - $90 \mathrm{mV}$ (Figure 5a). Cross section show a thicker, porous layer $(\sim 2 \mu \mathrm{m})$ as compared to samples polarized at +130 mV (Figure 6b). Samples polarized at $+240 \mathrm{mV}$ (position 6 in Figure 1) once again show a dense corrosion layer of both organic and inorganic corrosion products (Figure 5d). The thickness of the layer was $<1 \mu \mathrm{m}$, (Figure 6c.)

\subsection{FTIR}

FTIR spectra from samples polarized at $+90 \mathrm{mV}$ vs OCP (Figure 7) in whole blood show striking similarity to reported spectra from the constituents of whole blood.[20, 21] The broad peak at $3300 \mathrm{~cm}^{-1}$ (Figure 7) is characteristic of $\mathrm{N}-\mathrm{H}$ and $\mathrm{O}-\mathrm{H}$ stretching vibrations. A series of peaks from $3000 \mathrm{~cm}^{-1}$ to $2850 \mathrm{~cm}^{-1}$ corresponds to $\mathrm{H}-\mathrm{C}$ stretching and confirms the presence of organic substance on the surface. The strong peak at $1650 \mathrm{~cm}^{-1}$ is assigned to $\mathrm{C}=\mathrm{O}$ stretching (amide I vibration). [21] The band around $1550 \mathrm{~cm}^{-1}$ corresponds to the amide II vibration and is an out of phase combination of C$\mathrm{N}$ stretching and $\mathrm{N}-\mathrm{H}$ bending.[21] The peak at $1460 \mathrm{~cm}^{-1} \mathrm{can}$ be ascribed to $\mathrm{C}-\mathrm{H}$ bending and the peak at $1400 \mathrm{~cm}^{-1}$ to the symmetric stretching of $\mathrm{COO}$. The peak at $1200 \mathrm{~cm}^{-1}$ is assigned to $\mathrm{PO}_{4}^{2-}$ symmetric stretching and in phase combination of $\mathrm{C}-\mathrm{N}$ stretching and $\mathrm{N}-\mathrm{H}$ bending (amide III vibration).[21] The peak at $1100 \mathrm{~cm}^{-1}$ can be associated with C-C, C-O,[21] or $\mathrm{PO}_{4}{ }^{2-}$ stretching.[22] Samples polarized at more anodic potentials show the same peaks as the samples polarized at + $90 \mathrm{mV}$ correlating to the adsorbed proteins. However, close inspection of the peak at $\sim 1100 \mathrm{~cm}^{-1}$ (associated with $\mathrm{PO}_{4}{ }^{2-}$ modes) show increasing intensity with overpotential (insert in Figure 7). The $\mathrm{PO}_{4}^{2-}$ peak can be separated into five peaks, indicated by arrows in the insert, at $1110 \mathrm{~cm}^{-1}\left(v_{3}\right), 1070 \mathrm{~cm}^{-1}\left(v_{3}\right), 1020 \mathrm{~cm}^{-1}\left(v_{3}\right), 955 \mathrm{~cm}^{-1}$ $\left(v_{1}\right)$, and $835 \mathrm{~cm}^{-1}$ (water liberational modes).[22] Compared to samples polarized at $+90 \mathrm{mV}$ the intensity of the peak at $1020 \mathrm{~cm}^{-1}$ increase for samples polarized at the higher potentials. The peaks at $955 \mathrm{~cm}^{-1}$ and $835 \mathrm{~cm}^{-1}$, were not observed at $+90 \mathrm{mV}$. The peaks at $1015 \mathrm{~cm}^{-1}, 955 \mathrm{~cm}^{-1}$, and $835 \mathrm{~cm}^{-1}$ 
are therefore interpreted as originating from the inorganic component of the protective corrosion layer. A candidate structure of the inorganic component, characterized by peaks at the same wavenumbers, is Spencerite $\left(\mathrm{Zn}_{4}\left(\mathrm{PO}_{4}\right)_{2}(\mathrm{OH})_{2} \cdot 3 \mathrm{H}_{2} \mathrm{O}\right)$. [23]

\section{Discussion}

A commonly proposed reaction mechanism for zinc dissolution at neutral $\mathrm{pH}$ in chloride containing solutions is a two-step mechanism involving a $\mathrm{Zn}^{+}$adsorbate intermediate. [18, 24]

$Z \stackrel{k_{1}}{\leftrightarrow} Z n^{+}(a d s)+e^{-}$

$Z n^{+}(a d s) \stackrel{k_{2}}{\leftrightarrow} Z n^{2+}(a d s)+e^{-} \stackrel{k_{3}}{\leftrightarrow} Z n^{2+}(s o l)$

$\left(\frac{1}{2} \mathrm{O}_{2}+2 \mathrm{H}^{+} \leftrightarrow \mathrm{H}_{2} \mathrm{O}\right)$

$\mathrm{Zn}$ is oxidized to adsorbed $\mathrm{Zn}+$ intermediate in a first electron transfer step (reaction I) and

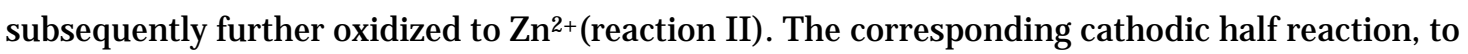
preserve electro neutrality, is oxygen reduction (reaction III). $\mathrm{k}_{1} \mathrm{k}_{2}$ and $\mathrm{k}_{3}$ are the rate constants of reactions I to III. The electrochemical impedance response of a system with adsorbates as intermediates can be described by a double layer capacitance $\mathrm{C}_{\mathrm{DL}}$ in parallel with a faradic impedance $\mathrm{Z}_{\mathrm{f}}[18,19,25]$ :

$$
\frac{1}{Z_{f}}=\frac{1}{R_{t}}+\sum_{n=1}^{m}\left(\frac{\partial i}{\partial \theta_{n}}\right)_{E} \frac{\Delta \theta_{n}}{\Delta E}
$$

Where $R_{t}$ is the charge transfer resistance, $\theta_{n}$ is the surface coverage of the adsorbed intermediate $n$, and $m$ is the number of adsorbed intermediates. $C_{D L}$ and $R_{t}$ describes the first, high frequency, capacitive arc observed in the Nyquist plots. The second, low frequency, capacitive or inductive arc is characterized by the second term in Equation 2. This term defines the current response to a small sinusoidal potential perturbation, $\Delta \mathrm{E}$, resulting from changes in surface coverage of the adsorbed intermediate.[18] If ( $\partial \mathrm{i} / \partial \theta) \Delta \theta / \Delta \mathrm{E}$ is negative the response appears as a capacitive arc in the Nyquist 
plot. If on the other hand $(\partial \mathrm{i} / \partial \theta) \Delta \theta / \Delta \mathrm{E}$ is positive the observed response is an inductive arc. Assuming the second electron transfer is the rate limiting step, the surface coverage of $\mathrm{Zn}^{+}, \theta_{1}$, increases when a positive $\Delta \mathrm{E}$ is applied and decreases if $\Delta \mathrm{E}$ is negative, i.e. $\Delta \theta_{1} / \Delta \mathrm{E}$ is positive. An increase in $\theta_{1}$ increases the current density $\mathrm{i}$, thus $(\partial \mathrm{i} / \partial \theta) \Delta \theta / \Delta \mathrm{E}$ is positive and the inductive arc observed in whole blood at $+90 \mathrm{mV}$ (Figure 2, point 2) corresponds to the relaxation of surface area $\theta_{1}$ in response to the applied perturbation $\Delta \mathrm{E}$. The anodic dissolution at this potential can best be described as active dissolution where corrosion occurs over the entire surface. During the stage of active dissolution organic species are loosely adsorbed on the surface as characterized by FTIR. The patches of organic material observed in SEM on the surface polarized at $+90 \mathrm{mV}$ are the dried remnants of these adsorbates (Figure 5a). The influence of the organic species on the faradic impedance is not clear in the observed frequency range as there is no distinct capacitive loop observed directly related to their adsorption. The double layer capacitance $\left(120 \mu \mathrm{s}^{n} \Omega^{-1} \mathrm{Cm}^{-2}\right.$, table 1 supplementary) is however higher than in common saline solutions.[17] This increase in double layer capacitance is tentatively due to the adsorbed organic species. The organic species may be adsorbed on the metallic surface or on top of the adsorbed intermediates.

Following the method described by Giménes-Romero et al. the rate constants $\mathrm{k}_{1}$ to $\mathrm{k}_{3}$ are calculated from three characteristic points of the EIS spectra.[24] The first point is the impedance when the frequency approaches zero, when the response depends on all kinetic parameters of the faradic process. The second point is where the imaginary impedance is zero, thus the response depends only on the kinetic parameters of the first electron transfer. The third point is the point of maximum imaginary impedance which depends on the kinetic parameters of the first and second electron transfer but not on the diffusion reaction.[24] Once the kinetic parameters have been obtained the surface area fractions covered by $\mathrm{Zn}^{\circ}, \mathrm{Zn}^{+}$and $\mathrm{Zn}^{2+}$ can be calculated.[26] The obtained surface coverage of $\mathrm{Zn}+$ at $+90 \mathrm{mV}$ in whole blood is between $50 \%$ and $60 \%$, the surface coverage of $\mathrm{Zn}^{2+}$ is $40-50 \%$ and the surface coverage of $\mathrm{Zn}^{0}$ is less than $0.1 \%$. The calculated kinetic constants and surface coverages are included as Table 2 in the supplementary information. The adsorbed $\mathrm{Zn}$ ions produced by the anodic reaction in whole blood may subsequently react with phosphate ions to produce a zinc phosphate protective layer, with a corresponding surface coverage $\theta_{2}$. The layer of organic components formed at OCP tentatively hinders the diffusion and adsorption of $\mathrm{PO}_{4}^{3-}$ to the metal surface. However, as increasing anodic overpotential are applied the diffusion of $\mathrm{PO}_{4}{ }^{3-}$ to the samples surface is expected to increase due to the increase in driving force. In order for the 
protective layer to nucleate and grow a threshold surface coverage of $\mathrm{Zn}$ ions and $\mathrm{PO}_{4}{ }^{3-}$ is required. This threshold coverage is only reached at overpotentials above approximately $+110 \mathrm{mV}$. The nucleation is indicated by the decrease in current density observed in PDP measurements in whole blood (Figure 1). At this potential the inductive arc observed at $+90 \mathrm{mV}$ decreases and is replaced by a capacitive arc. This is interpreted as a decrease in surface coverage of $\mathrm{Zn}^{+}\left(\theta_{1}\right)$ and increase of the coverage of zinc phosphate $\left(\theta_{2}\right)$ with increasing overpotential. The zinc phosphate layer hinders the corrosion and as a result of the increasing $\theta_{2}$ the current density decreases at potentials above $+110 \mathrm{mV}$ vs OCP. (Figure 1) The surface area covered by the phosphate layer, $\theta_{2}$, correspond to the second, low frequency, capacitive arc observed at $+130 \mathrm{mV}$ and $+180 \mathrm{mV}$ (Figure 2, position 3 and 4). At $+130 \mathrm{mV}$ the surface is completely covered by a thin layer of zinc phosphate and adsorbed organic species. As the potential is increased to $+180 \mathrm{mV}$ the zinc phosphate layer grows in thickness, in agreement with the increase in resistance obtained from the EIS data fits. (Figure 2, position 3 and 4) However, the amount of adsorbed organic species does not appear to increase between $+130 \mathrm{mV}$ and $180 \mathrm{mV}$ as only patches of organic material was observed on the surface of samples polarized at $+180 \mathrm{mV}$ (Figure $5 \mathrm{c}$ ). Increasing the overpotential above $+180 \mathrm{mV}$ results in an increase in the current density (Figure 1, point 5) due to a breakdown of the protective zinc phosphate layer. The inductive arc that is observed at $+210 \mathrm{mV}$ (Figure 2, position 5) is associated with the relaxation of the surface area no longer protected by the phosphate layer $\left(\theta_{3}\right)$. Similar to the inductive response previously described for the $\mathrm{Zn}^{+}$surface coverage $\left(\theta_{1}\right)$ in the potential range from $0 \mathrm{mV}$ to $110 \mathrm{mV}$, the coverage of the exposed surface areas $\left(\theta_{3}\right)$ will increase with increasing potential. Further, the current density increases with increasing $\theta_{3}$, thus resulting in the inductive response observed in Figure 2, position 5 according to equation 2.

The second passivation observed at $+240 \mathrm{mV}$ and the second capacitive arc observed in the Nyquist plot (Figure 2, position 6) is associated with an increased amount of organic material on the sample surface observed in the SEM analysis (Figures $5 \mathrm{~d}$ and $6 \mathrm{c}$ ). This increase in protein adsorption is tentatively related to the applied potential rather than the anodic dissolution. Proteins carry charges and their adsorption onto surfaces depends on the surface charge.[27] Any number of proteins and other species present in the whole blood could be involved in this rapid adsorption process. The precise causes of the adsorption and subsequent current decrease are therefore beyond the scope of this paper. 
Although the protective layer formed in whole blood largely consisted of a zinc phosphate the current decrease during anodic polarization (indicating the protective layer formation) was only observed in whole blood and not in $\mathrm{m}$-SBF. It is clear that the organic species in whole blood are necessary for the layer to form. The anodic polarization of zinc in $\mathrm{m}-\mathrm{SBF}$ is characterized by a protective layer but of a very different nature than the layer formed in whole blood. Unlike the samples polarized in whole blood the Nyquist plots of samples polarized in m-SBF show only one capacitive arc and no inductive arc (Figure 3). The single high frequency arc observed by EIS signifies that the surface solution interface is dominated by the charge transfer reaction and double layer capacitance. The lack of a low frequency arc (inductive or capacitive) suggests that any adsorbed intermediates have a negligible effect on the electrochemical reactions. A significant decrease in the first electron transfer would limit the surface coverage of $\mathrm{Zn}^{+}$and $\mathrm{Zn}^{2+}$ and entail the single arc impedance response.[24] The relative decrease in current density observed in the PDP measurements, compared to samples immersed in whole blood, (Figure 1) is also consistent with a decrease in the electron transfer rate. These results can be explained by the presence of a thin protective layer impeding the electron transfer. Phosphate ions are known to passivate zinc by adsorption and formation of a monolayer of glassy $\mathrm{NaZnPO} 4 \cdot \mathrm{H}_{2} \mathrm{O} \cdot[28]$ Unlike the protective layer formed in whole blood the layer in $\mathrm{m}$-SBF forms already at OCP and suppresses the corrosion more efficiently, limiting the corrosion up to $120 \mathrm{mV}$. Optical inspection of samples polarized below $120 \mathrm{mV}$ revealed a polished metallic surface, virtually unaffected by the applied potential. The passivating layer is too thin to be visible. As a consequence of the limited corrosion, the critical surface coverage of $\mathrm{Zn}$ ions required to form the protective $\mathrm{Zn}_{4}\left(\mathrm{PO}_{4}\right)_{2}(\mathrm{OH})_{2} \cdot 3 \mathrm{H}_{2} \mathrm{O}$ layer (formed in whole blood) is not reached below the pitting potential. Above the pitting potential the current density increases. However, the anodic reaction only occurs on a small fraction of the sample surface penetrating deep into the sample matrix, i.e. pitting. Hence there is never sufficient amount of $\mathrm{Zn}$ ions available for the $\mathrm{Zn}_{4}\left(\mathrm{PO}_{4}\right)_{2}(\mathrm{OH})_{2} \cdot 3 \mathrm{H}_{2} \mathrm{O}$ layer to form in $\mathrm{m}$-SBF. In whole blood no protective film forms at $\mathrm{OCP}$ (as in $\mathrm{m}-\mathrm{SBF}$ ) despite the presence of $\mathrm{PO}_{4}{ }^{2-}$ in the biological solution. The adsorption of organic components is suggested to hinder the $\mathrm{PO}_{4}{ }^{2-}$ adsorption and initial film formation. The lack of initial passivation enhances the initial corrosion. At low overpotentials the increased corrosion results in a large fraction of the metallic surface to be covered by $\mathrm{Zn}$ ions. The application of anodic overpotentials also increases the driving force for $\mathrm{PO}_{4}{ }^{2-}$ diffusion through the adsorbed organic components. At the critical overpotential ( $>+110 \mathrm{mV}$ ) there is sufficient $\mathrm{Zn}$ ions and $\mathrm{PO}_{4}^{2-}$ to react and form the protective $\mathrm{Zn}_{4}\left(\mathrm{PO}_{4}\right)_{2}(\mathrm{OH})_{2} \cdot 3 \mathrm{H}_{2} \mathrm{O}$ coating at the interface. 


\section{Conclusions}

The formation of a protective layer on zinc in whole blood during anodic polarization was studied by electrochemical impedance spectroscopy. The surface at low overpotential is characterized by an active dissolution mechanism involving a $\mathrm{Zn}^{+}$intermediate as inferred from the presence of an inductive arc in the EIS spectra. At increasing anodic overpotential a protective corrosion layer is formed by the reaction between $\mathrm{Zn}$ ions and $\mathrm{PO}_{4}^{2-}$ to form $\mathrm{Zn}_{4}\left(\mathrm{PO}_{4}\right)_{2}(\mathrm{OH})_{2} \cdot 3 \mathrm{H}_{2} \mathrm{O}$. This reaction does not occur in $\mathrm{m}$ $\mathrm{SBF}$ which contains $\mathrm{PO}_{4}^{2-}$ but no organic species. In $\mathrm{m}-\mathrm{SBF}$ the phosphates from the electrolyte passivates the surface already at the corrosion potential. There is thus only a slow release of $\mathrm{Zn}$ ions during anodic polarization below the pitting potential in $\mathrm{m}-\mathrm{SBF}$, and no formation of $\mathrm{Zn}_{4}\left(\mathrm{PO}_{4}\right)_{2}(\mathrm{OH})_{2} \cdot 3 \mathrm{H}_{2} \mathrm{O}$ can occur. We conclude that rapid adsorption of proteins on the $\mathrm{Zn}$ surface immersed in whole blood prevents the initial passivation by $\mathrm{PO}_{4}{ }^{2-}$ observed in $\mathrm{m}-\mathrm{SBF}$. The protein adsorption results in an increased initial corrosion rate and increased formation of $\mathrm{Zn}$ ions. The increase in $\mathrm{Zn}$ ions subsequently (at higher overpotential) allows for the formation of the protective $\mathrm{Zn}_{4}\left(\mathrm{PO}_{4}\right)_{2}(\mathrm{OH})_{2} \cdot 3 \mathrm{H}_{2} \mathrm{O}$ layer. This finding is an important step toward understanding the role of organic species in zinc degradation in clinical situations.

\section{Acknowledgement}

Abbott and the Swedish research council are acknowledged for their financial support. The authors would also like to acknowledge Dr. Gaolong Cao and Dr. Luca Piazza for assistance with obtaining the FIB-SEM images and Dr. Anna Norlin Weissenrieder for valuable discussions.

\section{References}

[1] P.K. Bowen, E.R. Shearier, S. Zhao, R.J . Guillory, F. Zhao, J . Goldman, J.W. Drelich, Biodegradable Metals for Cardiovascular Stents: from Clinical Concerns to Recent Zn-Alloys, Advanced Healthcare Materials 5(10) (2016) 1121-1140.

[2] P. Erne, M. Schier, T.J . Resink, The road to bioabsorbable stents: Reaching clinical reality?, Cardiovascular and Interventional Radiology 29(1) (2006) 11-16.

[3] F. Witte, V. Kaese, H. Haferkamp, E. Switzer, A. Meyer-Lindenberg, C.J . Wirth, H. Windhagen, In vivo corrosion of four magnesium alloys and the associated bone response, Biomaterials 26(17) (2005) 3557-3563.

[4] M. Peuster, P. Wohlsein, M. Brugmann, M. Ehlerding, K. Seidler, C. Fink, H. Brauer, A. Fischer, G. Hausdorf, A novel approach to temporary stenting: degradable cardiovascular stents produced from corrodible metal - results 6-18 months after implantation into New Zealand white rabbits, Heart 86(5) (2001) 563-569. 
[5] Y.F. Zheng, X.N. Gu, F. Witte, Biodegradable metals, Materials Science \& Engineering R-Reports 77 (2014) 1-34.

[6] D. Pierson, J . Edick, A. Tauscher, E. Pokorney, P. Bowen, J . Gelbaugh, J. Stinson, H. Getty, C.H. Lee, J . Drelich, J . Goldman, A simplified in vivo approach for evaluating the bioabsorbable behavior of candidate stent materials, J ournal of Biomedical Materials Research Part B-Applied Biomaterials 100B(1) (2012) 58-67.

[7] K. Bobe, E. Willbold, I. Morgenthal, O. Andersen, T. Studnitzky, J . Nellesen, W. Tilmann, C. Vogt, $\mathrm{K}$. Vano, F. Witte, In vitro and in vivo evaluation of biodegradable, open-porous scaffolds made ofsintered magnesium W4 short fibers, Acta Biomaterialia (2013).

[8] K. Törne, A. Örnberg, J. Weissenrieder, Influence of strain on the corrosion of magnesium alloys and zinc in physiological environments, Acta Biomaterialia 48 (2017) 541-550.

[9] N. Winzer, A. Atrens, G.L. Song, E. Ghali, W. Dietzel, K.U. Kainer, N. Hort, C. Blawert, A critical review of the stress corrosion cracking (SCC) of magnesium alloys, Advanced Engineering Materials 7(8) (2005) 659-693.

[10] D. Vojtech, J . Kubasek, J . Serak, P. Novak, Mechanical and corrosion properties of newly developed biodegradable Zn-based alloys for bone fixation, Acta Biomaterialia 7(9) (2011) 3515-3522.

[11] K. Törne, M. Larsson, A. Norlin, J . Weissenrieder, Degradation of zinc in saline solutions, plasma, and whole blood, J Biomed Mater Res Part B 00(00) (2015) 000-000.

[12] P.K. Bowen, J . Drelich, J . Goldman, Zinc Exhibits Ideal Physiological Corrosion Behavior for Bioabsorbable Stents, Advanced Materials 25(18) (2013) 2577-2582.

[13] H.F. Li, X.H. Xie, Y.F. Zheng, Y. Cong, F.Y. Zhou, K.J . Qiu, X. Wang, S.H. Chen, L. Huang, L. Tian, L. Qin, Development of biodegradable Zn-1X binary alloys with nutrient alloying elements $\mathrm{Mg}$, Ca and Sr, Scientific Reports 5 (2015) 13.

[14] A.J . Drelich, S. Zhao, R.J. Guillory, J.W. Drelich, J . Goldman, Long-term surveillance of zinc implant in murine artery: Surprisingly steady biocorrosion rate, Acta Biomaterialia (2017).

[15] P.K. Bowen, R.J . Guillory, E.R. Shearier, J.M. Seitz, J . Drelich, M. Bocks, F. Zhao, J . Goldman, Metallic zinc exhibits optimal biocompatibility for bioabsorbable endovascular stents, Materials Science \& Engineering C-Materials for Biological Applications 56 (2015) 467-472.

[16] A. Oyane, H.M. Kim, T. Furuya, T. Kokubo, T. Miyazaki, T. Nakamura, Preparation and assessment of revised simulated body fluids, J ournal of Biomedical Materials Research Part A 65A(2) (2003) 188-195.

[17] M. Orazem, B. Tribollet, Electrochemical Impedanace Spectroscopy, J ohn Wiely and Sons Inc., Hoboken, NewJ ersey, 2008.

[18] C. Cachet, R. Wiart, Reaction-mechanism for zinc dissolution in chloride electrolytes, J ournal of Electroanalytical Chemistry 129(1-2) (1981) 103-114.

[19] G. Song, A. Atrens, D. St J ohn, X. Wu, J . Nairn, The anodic dissolution of magnesium in chloride and sulphate solutions, Corrosion Science 39(10-11) (1997) 1981-2004.

[20] T. Makhnii, O. Ilchenko, A. Reynt, Y. Pilgun, A. Kutsyk, D. Krasnenkov, M. Ivasyuk, V. Kukharskyy, AGE-RELATED CHANGES IN FTIR AND RAMAN SPECTRA OF HUMAN BLOOD, Ukrainian J ournal of Physics 61(10) (2016) 853-862.

[21] A. Barth, Infrared spectroscopy of proteins, Biochimica Et Biophysica Acta-Bioenergetics 1767(9) (2007) 1073-1101.

[22] R.L. Frost, An infrared and Raman spectroscopic study of natural zinc phosphates, Spectrochimica Acta Part a-Molecular and Biomolecular Spectroscopy 60(7) (2004) 1439-1445.

[23] N. Chukanov V, Infrared spectra of mineral species, Springer Science+Business Media, Dordrecht, 2014.

[24] D. Gimenez-Romero, J .J . Garcia-J areno, F. Vicente, Analysis of an impedance function of zinc anodic dissolution, J ournal of Electroanalytical Chemistry 572(2) (2004) 235-247.

[25] M. Keddam, Anodic dissolution, in: P. Marcus (Ed.), Corrosion Mechanisms in Theory and Practice, Marcel Dekker Inc., New York, NY, USA, 2002.

[26] D. Gimenez-Romero, J J . Garcia-J areno, F. Vicente, Kinetics of zinc anodic dissolution from the EIS characteristic points, Electrochemistry Communications 5(8) (2003) 722-727.

[27] B. Guo, J . Anzai, T. Osa, Adsorption behavior of serum albumin on electrode surfaces and the effects of electrode potential, Chemical \& Pharmaceutical Bulletin 44(4) (1996) 800-803.

[28] C.P. Depauli, O.A.H. Derosa, M.C. Giordano, Zinc dissolution and passivation in buffered phosphate solutions .1. comparative-study with sodium hydroxide solutions, Journal of Electroanalytical Chemistry 86(2) (1978) 335-348. 


\section{Figure caption}

Figure 1: PDP scan of zinc in whole blood after $30 \mathrm{~min}$ immersion. Arrows indicate potentials at which presented impedance spectra were collected. 1 OCP, $2+90 \mathrm{mV}$ (active dissolution), $3+130$ $\mathrm{mV}$ (protective layer formation), $4+180 \mathrm{mV}$ (continued protective layer formation), $5+210 \mathrm{mV}$ (breakdown of protective layer), $6+240 \mathrm{mV}$ (second protective layer). Insert shows PDP scan in whole blood (black, line) and m-SBF (red, dashed line).

Figure 2: Nyquist plots of impedance spectra obtained during anodic polarization of zinc in whole blood. The applied potentials are indicated by arrows in Figure 1. The scatter indicates data points and the line fitted data.

Figure 3: Nyquist plots obtained during anodic polarization of zinc in $\mathrm{m}-\mathrm{SBF}$. Insert is a magnification for improved visualization of the data collected at $+110 \mathrm{mV}$. The scatter indicates data points and the line fitted data.

Figure 4: Equivalent circuits used to fit the collected impedance spectra. a) Surface with a protective layer, bi-layer model, b) surface with adsorbed intermediates, active dissolution and c) surface with a partially protective layer, protective layer breakdown.

Figure 5: SEM surface images of samples polarized for $6 \mathrm{~h}$ at a) $+90 \mathrm{mV}$ vs OCP, active dissolution, b) $+130 \mathrm{mV}$, early protective layer, c) $+180 \mathrm{mV}$, growt of protective layer, and d) $230 \mathrm{mV}$, second protective layer.

Figure 6: SEM cross section images of samples polarized for $6 \mathrm{~h}$ at a) $+130 \mathrm{mV}$ vs OCP, b) $+180 \mathrm{mV}$, and c) $+230 \mathrm{mV}$. The lines indicate the corrosion layer cross section. In $\mathrm{b}$ the dashed lines indicate an observed pore.

Figure 7: FTIR spectrum from a zinc sample polarized for $6 \mathrm{~h}$ at $+90 \mathrm{mV}$ vs OCP. Peaks indicated by arrows are assigned as O-H and N-H (3300 cm-1), C-H (3000 - $2800 \mathrm{~cm}^{-1}$, amide I (1650 cm-1), amide II $\left(1550 \mathrm{~cm}^{-1}\right), \mathrm{C}-\mathrm{H}\left(1460 \mathrm{~cm}^{-1}\right), \mathrm{COO}\left(1400 \mathrm{~cm}^{-1}\right)$, amide III $\left(1250 \mathrm{~cm}^{-1}\right)$ and C-C, CO or PO $4\left(1100 \mathrm{~cm}^{-}\right.$ 1). Insert shows the relevant spectral region for the $\mathrm{PO}_{4}^{-2}$ peak of samples polarized at $1050-910 \mathrm{mV}$. 
Arrows indicate peaks at 1100, 1070, 1020, 950 and $835 \mathrm{~cm}^{-1}$ identifying the corrosion product as Spencerite.[23] 


\section{Figures}

Graphical abstract

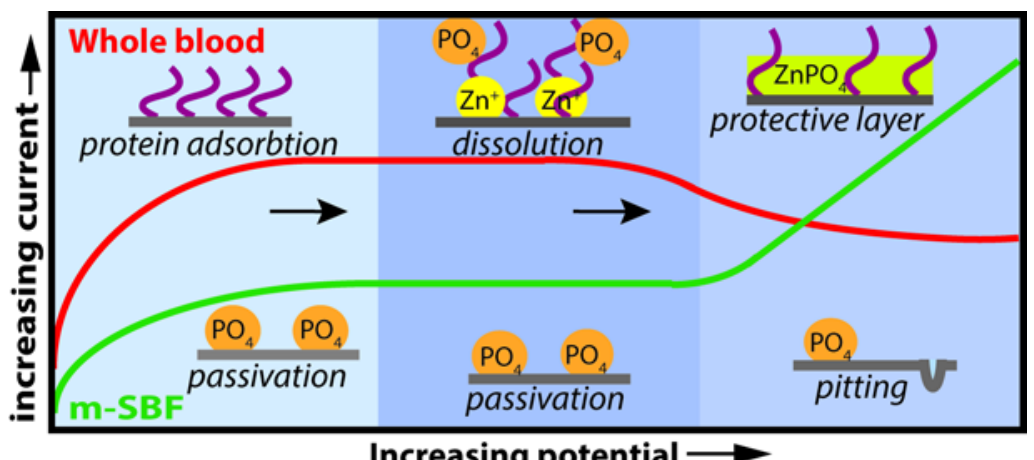

Figure 1

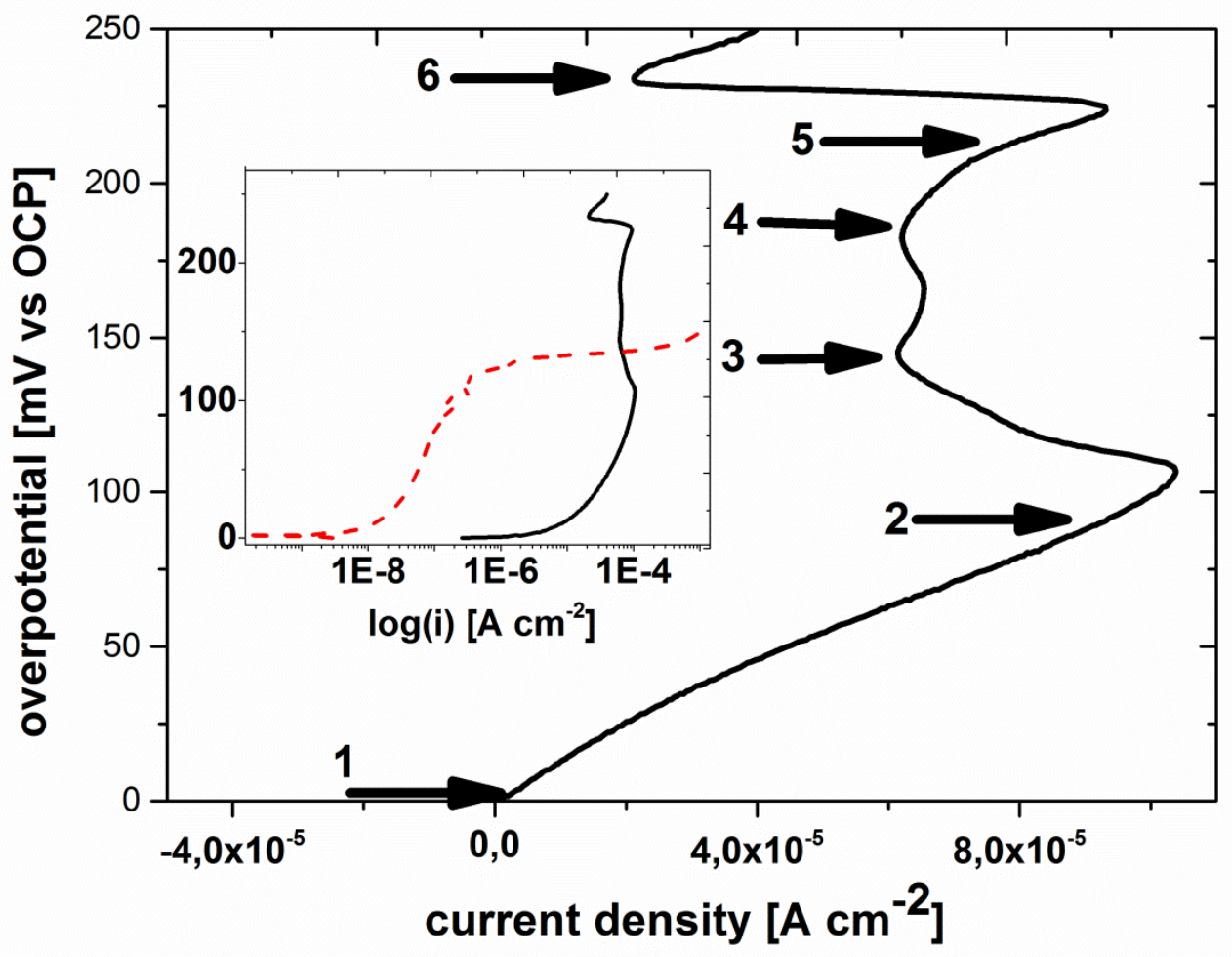


Figure 2

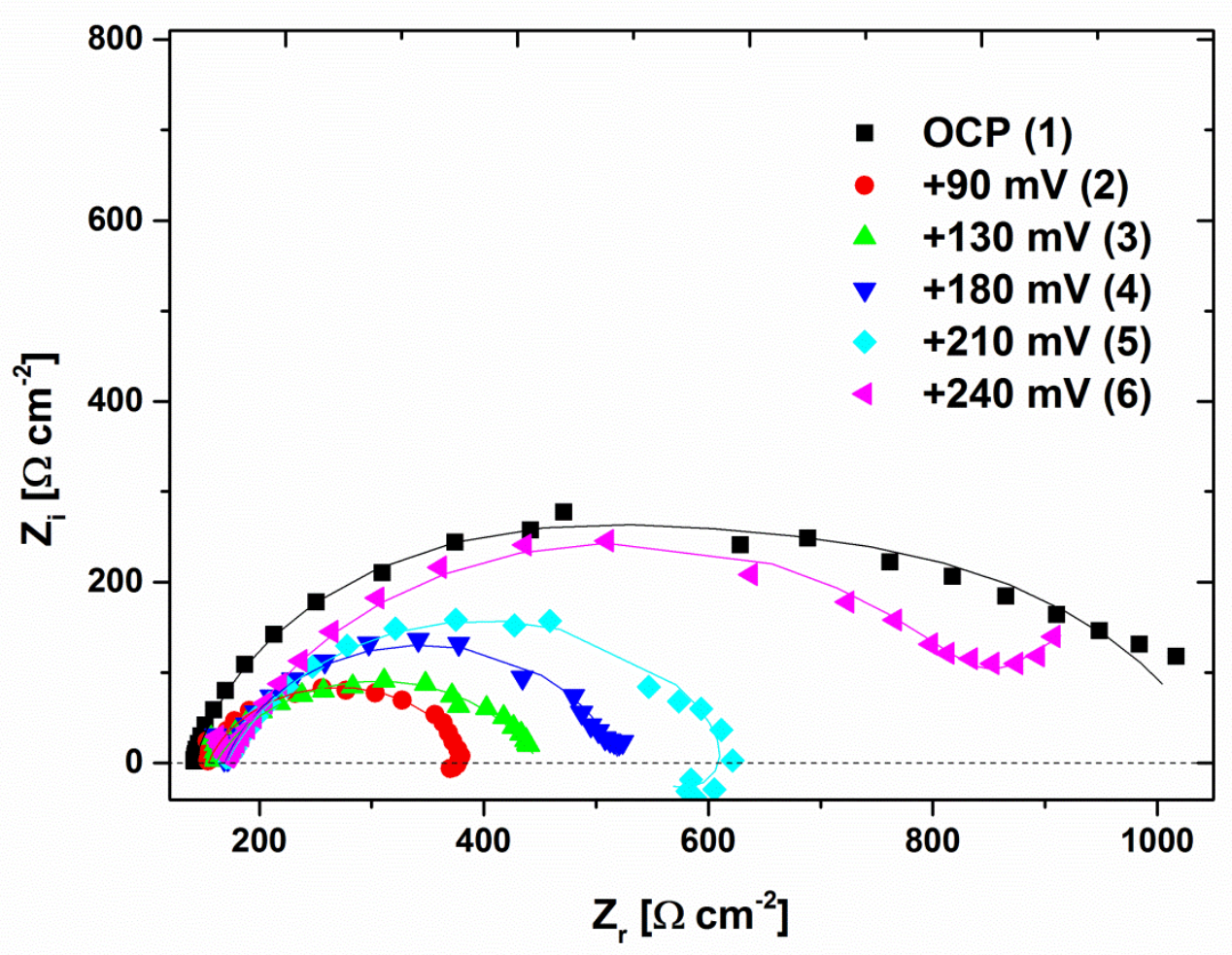

Figure 3

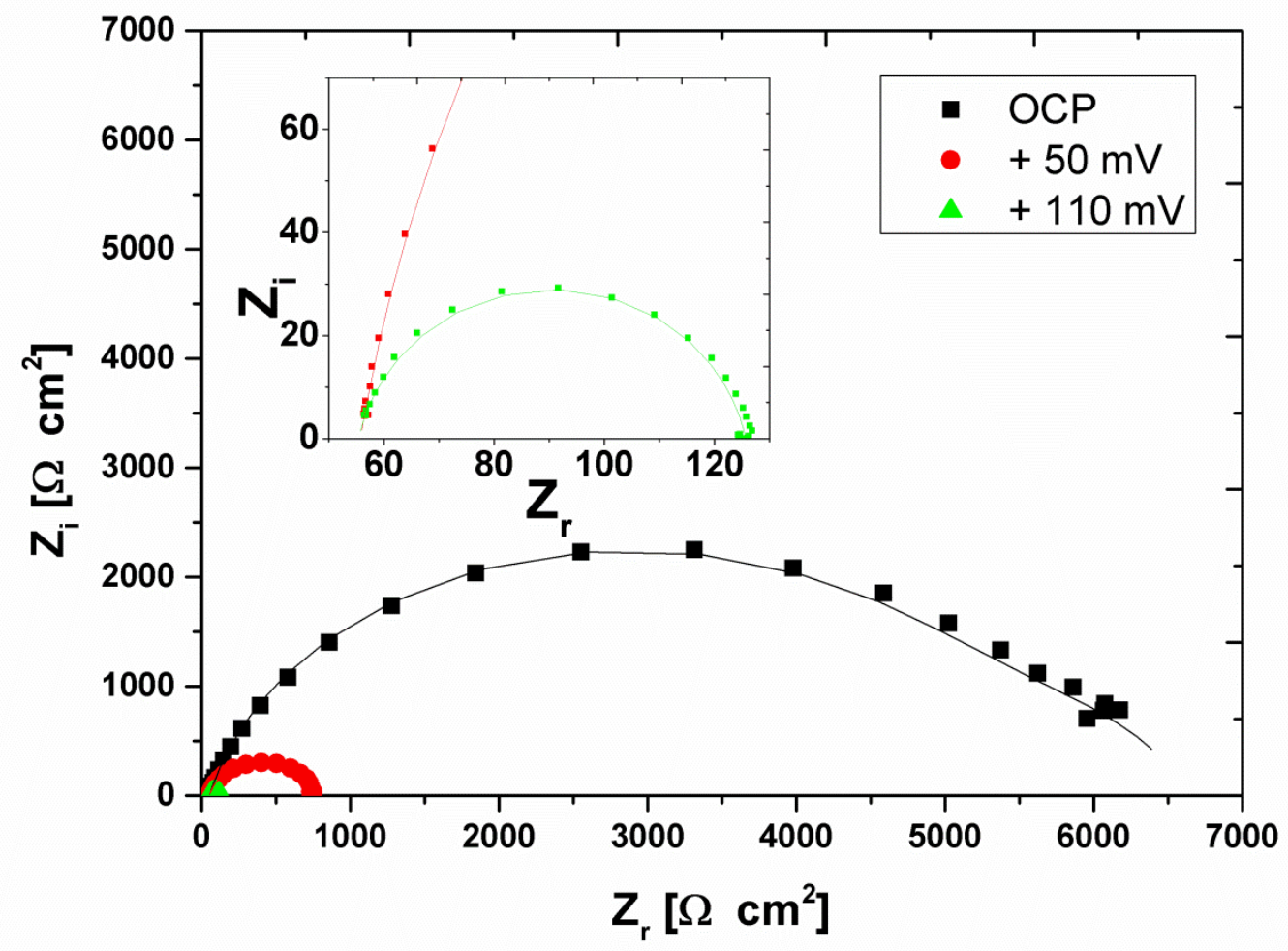


Figure 4

a)

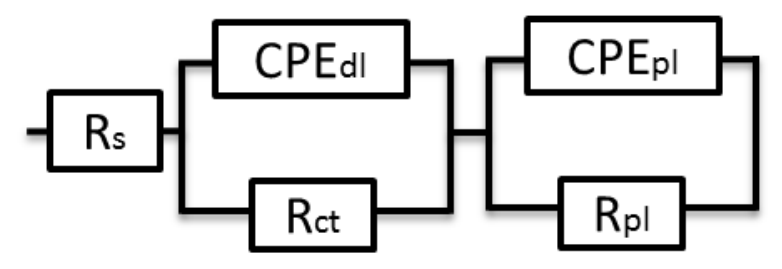

b)
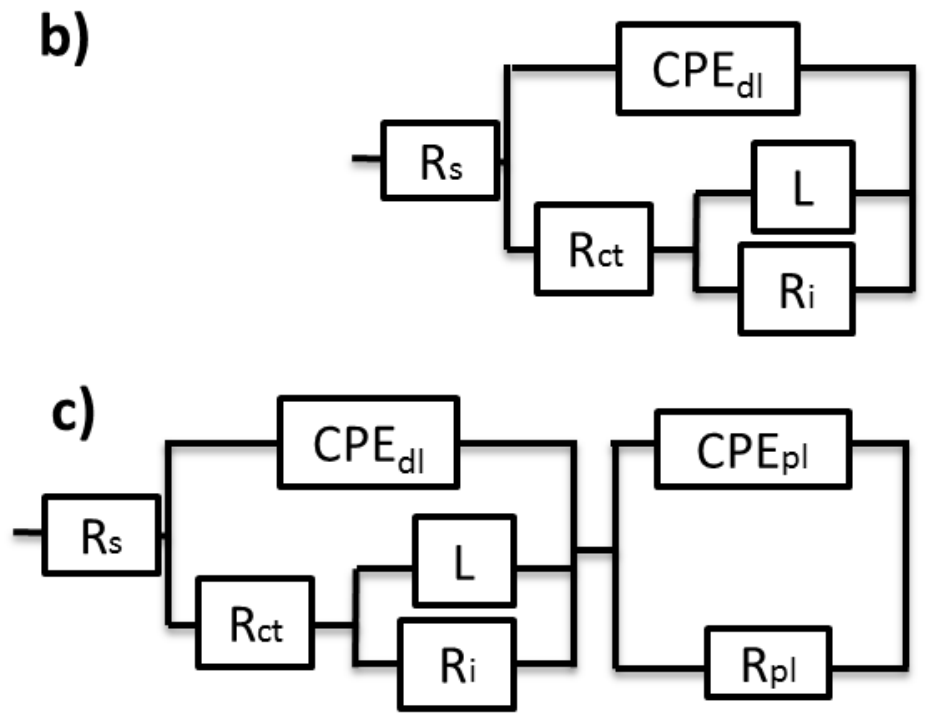

Figure 5
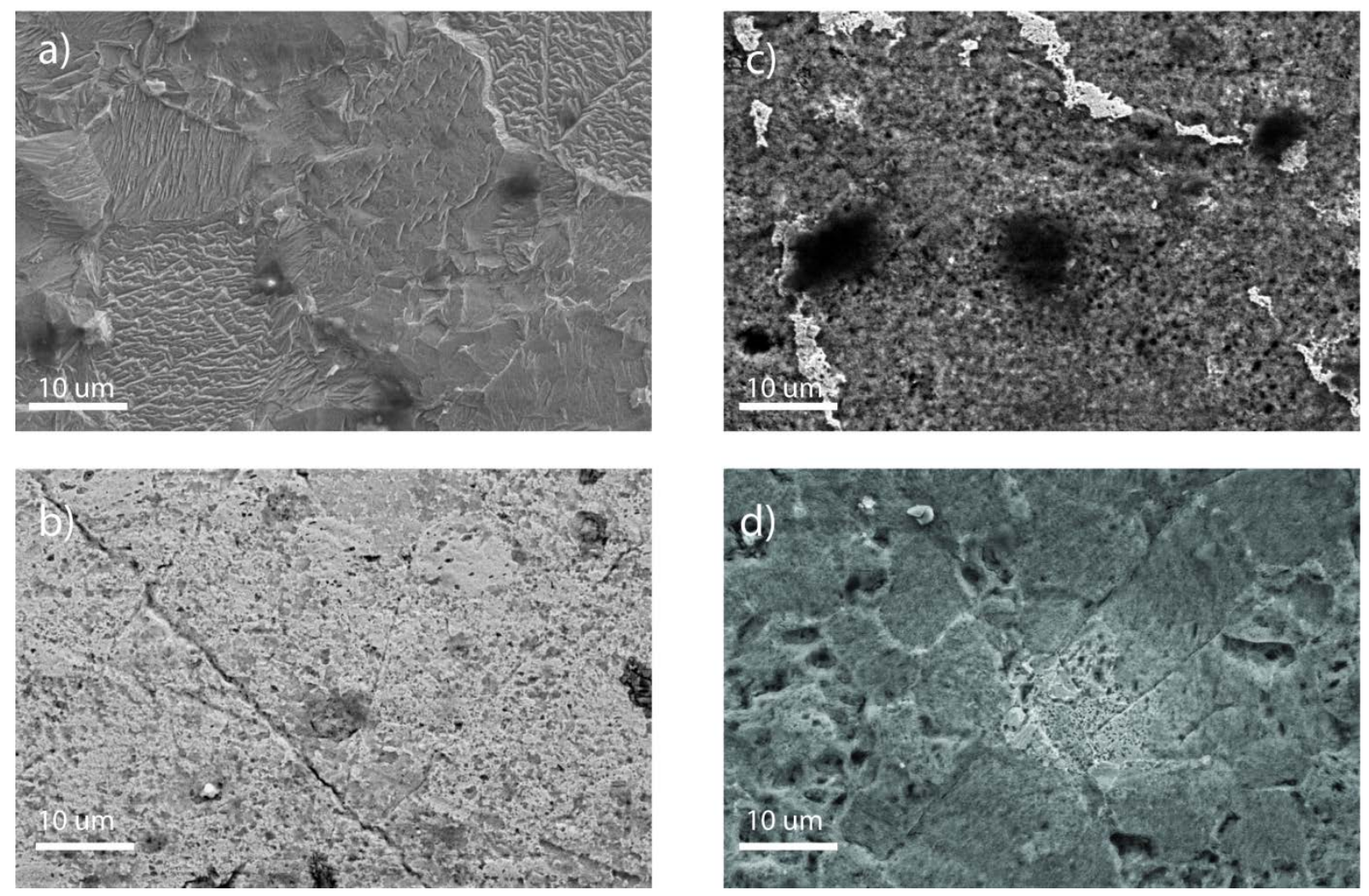
Figure 6
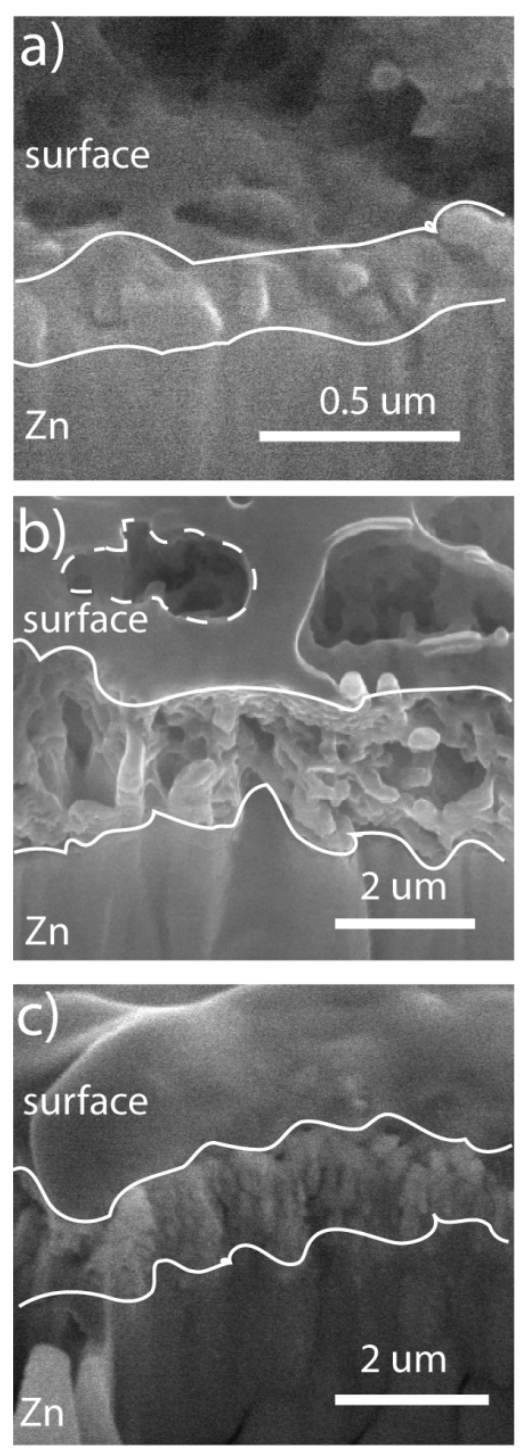
Figure 7

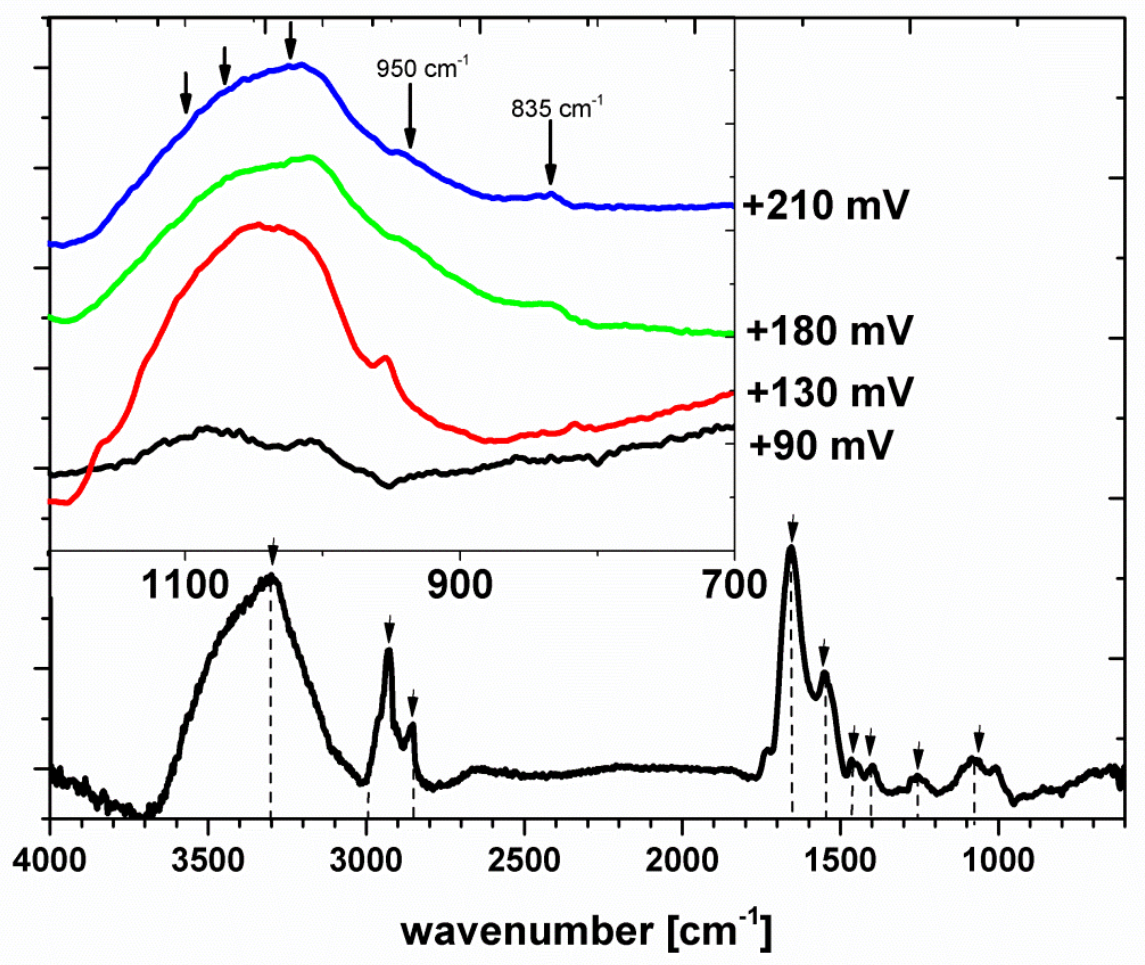

